\title{
DETERMINING MATERNITY CASE LOAD BY MEANS OF A POISSON PROCESS
}

\author{
BY \\ PETER COWAN, A.R.I.B.A, AND KENYON ROTH \\ Hospital Research Project, University College, London
}

While planning a new maternity teaching hospital, we encountered the problem of relating number of delivery rooms to expected case load. The flow of patients in the teaching and research sections of the hospital could be predicted on the basis of previous experience, but for an attached "sector unit" the problem was much more difficult. The unit was intended to serve a new function, and therefore no case load data existed.

The existing maternity teaching hospital contains 85 beds. Most routine deliveries are excluded from this hospital and admitted elsewhere. A special unit of 45 beds for the professor of obstetrics is located some 2 miles away in the main university teaching hospital. It is intended to combine both these units in the new maternity teaching hospital.

In addition, a special "sector unit" is planned. This will provide for the routine maternity needs of

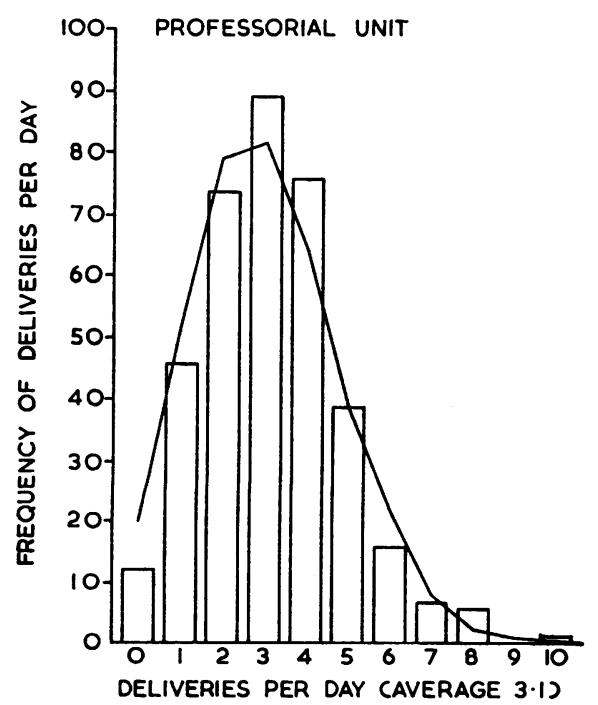

FIG. 1.-Existing frequencies of deliveries per day in 1960 compared with theoretical distribution (professorial unit). a population of some 120,000 living in the surrounding area. It will be mainly staffed by general practitioners and local authority midwives under consultant supervision. The "sector unit" will provide for all normal deliveries together with such minor abnormalities as low forceps delivery, manual removal of placenta, and some cases of surgical induction. It is proposed that all suitable cases should remain in the unit for only 24 hours, and that they should occupy only one room during their entire length of stay.

\section{METHOD}

The first step was to obtain an analysis of the frequency of deliveries per day throughout the year for each of the two existing facilities. These analyses were plotted as frequency histograms (Figs 1 and 2).

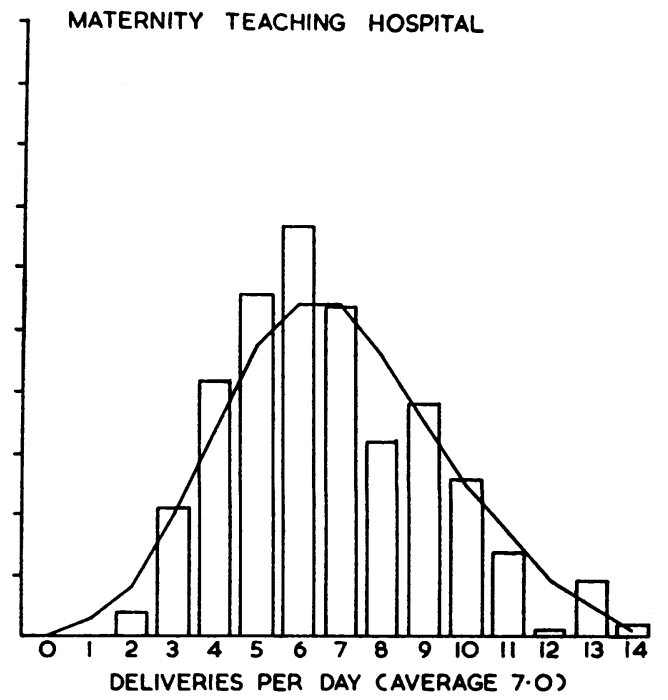

FIG. 2.-Existing frequencies of deliveries per day in 1960 compared with theoretical distribution (maternity teaching hospital). 
It can be seen that there is a difference in range between the professorial unit and the main teaching hospital. This is probably due to the different size and admission policies of the two units.

In order to check the variation in load falling upon a maternity unit throughout the year, we examined the statistics included in the report of the Maternity Services Committee (Ministry of Health, 1959) of births for England and Wales per month during 1956. We derived a monthly mean of 58,993 (Fig. 3).

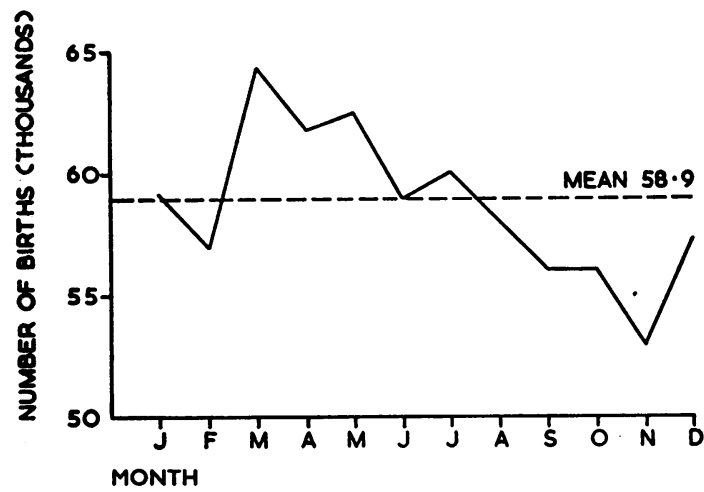

Fig. 3.-No. of births per month in England and Wales, 1956. (From report of Maternity Services Committee, 1959).

A seasonal variation in load occurred during the months February to June. These months showed an average increase of 4 per cent. over the monthly mean for the whole year. It seemed reasonable to base the average number of deliveries per day on an amended figure, which would take this variation into account. We derived this revised mean as follows:

$$
N m \frac{(M m \times S v)}{N d}=D
$$

where $D$ is the average number of deliveries per day,

$\mathrm{Nm}$ is the number of months when the seasonal load varies,

$M m$ is the monthly mean for the year,

$S v$ is the average increase over this period (1.04),

$N d$ is the number of days when the seasonal load varies (February-June inclusive).

Having obtained these data, it was necessary to discover whether they would be useful in calculating the anticipated future load upon the "sector unit".

The maternity case load has a random distribution in time. Blumberg (1961) suggested that the case load upon a maternity unit could be predicted by using a Poisson distribution. Thompson, Avant, and Spiker (1960) also showed that the queuing of cases through a maternity unit followed a Poisson distribution.
Such a distribution applies only to a random process, but it has the advantage that it can be simply constructed by the use of a mean.

In order to discover whether the case load falling upon the existing units exhibited random characteristics, and that a Poisson distribution would be a valid method of predicting future load, we decided to fit a Poisson distribution to the frequency histograms for the existing units. Using the amended daily mean as a basis (Professorial Unit $3 \cdot 1$; Maternity Teaching Unit 7.0) the constructed curves appeared to fit the histograms very closely (Figs 1 and 2). Checking the curves for goodness of fit, we applied the $\chi^{2}$ test and found no significant discrepancy between the two sets of data (Tables I and II).

TABLE I

MATERNITY TEACHING HOSPITAL

Average deliveries per day $6 \cdot 7$.

7. Amended average deliveries per day because of seasonal variations

\begin{tabular}{|c|c|c|c|c|}
\hline $\begin{array}{l}\text { Deliveries } \\
\text { per Day }\end{array}$ & $\begin{array}{c}\text { Observed } \\
\text { Frequencies } \\
\text { per Year }(n)\end{array}$ & $\begin{array}{c}\text { Poisson } \\
\text { Prediction } \\
\text { from } \\
\text { Molina's } \\
\text { Tables (z) }\end{array}$ & $\begin{array}{l}\text { Prediction } \\
\text { per Year } \\
\quad(v)\end{array}$ & $\underset{\substack{\text { Difference } \\
\text { e }}}{ }$ \\
\hline $\begin{array}{l}0 \\
1 \\
2 \\
3 \\
4 \\
5 \\
6 \\
7 \\
8 \\
9 \\
10 \\
11 \\
12 \\
13 \\
14 \\
15+\end{array}$ & $\begin{array}{r}0 \\
0 \\
4 \\
21 \\
42 \\
56 \\
67 \\
54 \\
32 \\
38 \\
26 \\
14 \\
1 \\
9 \\
2 \\
0\end{array}$ & $\begin{array}{l}.000912 \\
.006383 \\
.022341 \\
.052129 \\
.091226 \\
.127717 \\
.149003 \\
.149003 \\
.130377 \\
.101405 \\
.070983 \\
.045171 \\
.026350 \\
.014188 \\
.007094 \\
.005716\end{array}$ & 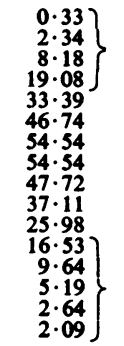 & $\begin{array}{r}4.93 \\
-8.61 \\
-9.26 \\
-12.46 \\
0.54 \\
15.72 \\
-0.89 \\
-0.02 \\
10.05\end{array}$ \\
\hline
\end{tabular}

TABLE II

PROFESSORIAL UNIT

Average deliveries per day $3 \cdot 1$.

\begin{tabular}{|c|c|c|c|c|}
\hline $\begin{array}{l}\text { Deliveries } \\
\text { per Day }\end{array}$ & $\begin{array}{c}\text { Observed } \\
\text { Frequencies } \\
\text { per Year }(n)\end{array}$ & $\begin{array}{c}\text { Poisson } \\
\text { Prediction } \\
\text { from } \\
\text { Molina's } \\
\text { Tables (z) }\end{array}$ & $\begin{array}{l}\text { Prediction } \\
\text { per Year } \\
(v)\end{array}$ & $\underset{v-n}{\text { Difference }}$ \\
\hline $\begin{array}{c}0 \\
1 \\
2 \\
3 \\
4 \\
5 \\
6 \\
7 \\
8 \\
9 \\
10 \\
11+\end{array}$ & $\begin{array}{l}12 \\
46 \\
74 \\
89 \\
76 \\
39 \\
16 \\
7 \\
6 \\
0 \\
1 \\
0\end{array}$ & $\begin{array}{l}.045049 \\
\cdot 139653 \\
\cdot 216461 \\
.223677 \\
.173350 \\
.107477 \\
.055530 \\
.024592 \\
.009529 \\
.003282 \\
.001018 \\
.000384\end{array}$ & $\left.\begin{array}{r}16.49 \\
51.11 \\
79.22 \\
81.87 \\
63.45 \\
39.34 \\
20.32 \\
9.00 \\
3.49 \\
1.20 \\
0.37 \\
0.14\end{array}\right\}$ & $\begin{array}{r}4.49 \\
5.11 \\
5 \cdot 22 \\
-7 \cdot 13 \\
-12.55 \\
0.34 \\
4.52\end{array}$ \\
\hline
\end{tabular}


We therefore inferred that the distribution of case load upon the existing facilities follows a Poisson distribution, and it seemed reasonable to use this as a guide to the expected case load for the "sector unit".

The expected number of deliveries per annum in the "sector unit" was estimated at approximately 1,400 (from a population of 120,000 , assuming ultimate 100 per cent. hospital delivery for all general practitioner cases). Therefore, the daily mean expectancy would be $3 \cdot 8$ or $4 \cdot 1$ deliveries (amended for seasonal variations). Using the Tables prepared by Molina (1942) for plotting Poisson distributions, and working with this mean ( $\mathrm{Z}$ in Molina's tables) we obtained a Poisson distribution for the expected case load (Fig. 4; Table III).

The maximum expectancy would be about ten

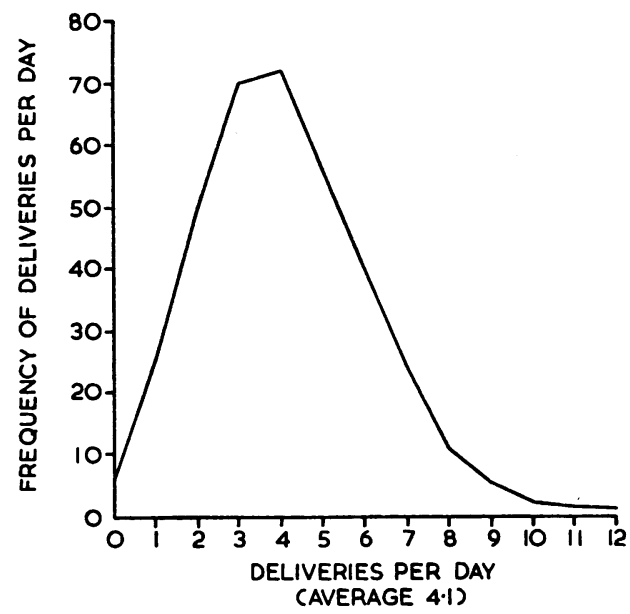

FIG. 4.-Theoretical distribution of deliveries per day for general practitioner sector unit.

TABLE III

\section{SECTOR UNIT}

Estimated annual deliveries 1,400 .

Average per day,over year $3 \cdot 8$.

Average per month 116.6 .

Average ratio of actual births to trend for February-June (inclusive) $1960=1 \cdot 047$

$116.6 \times 5=588.0$ births per 150 days

$$
\begin{aligned}
& \text { say } 117 \times 1 \cdot 047=122 \cdot 459 \\
& 112 \cdot 459 \times 5=612.295
\end{aligned}
$$$$
=4 \cdot 1 \text { births per day }
$$

with 100 per cent. hospital deliveries Sector unit average for peak period is $4 \cdot 1$ as opposed to $3 \cdot 8$ deliveries per day over the year.

\begin{tabular}{c|c|c}
\hline Deliveries per Day & $\begin{array}{c}\text { Poisson Prediction } \\
\text { from Molina's } \\
\text { Tables }(z)\end{array}$ & Prediction per Year \\
\hline 0 & $\cdot 016573$ & $6 \cdot 05$ \\
1 & .067948 & $24 \cdot 80$ \\
2 & $\cdot 139293$ & $50 \cdot 84$ \\
3 & $\cdot 190368$ & 69.48 \\
4 & $\cdot 195127$ & $71 \cdot 22$ \\
5 & $\cdot 160004$ & $58 \cdot 40$ \\
6 & $\cdot 109336$ & 39.91 \\
7 & .064040 & 23.38 \\
8 & .032820 & 11.98 \\
9 & .014951 & $5 \cdot 46$ \\
$10+$ & .009540 & 3.48 \\
\hline
\end{tabular}

or more deliveries per day. However, the probability of this would be only .0095 or one in 4 months. Therefore we decided that it would be most uneconomical to provide staff and accommodation for ten or more deliveries per day, and considered the probability of eight or more cases arriving in one day. From the curve the probability of this event is .0573 or one in every 18 days in the months with a high birth rate, rather less frequently in the other months. On the basis of a length of stay of 24 hours for each patient, and assuming that the patient occupies these particular rooms for the whole of her stay, there would be a relatively frequent need for eight such rooms.

If all patients arrived in the space of one hour, there would be a tremendous drain upon the staff and other resources. But the probability of even five arriving in the same hour is in the order of one in 114 years and it seemed unreasonable to base our plans on the likelihood of such an event occurring. Accordingly we decided to divide the day into units of 8 hours, and to calculate the probability of eight or more patients arriving during one of these 8-hr periods (Fig. 5; Table IV).

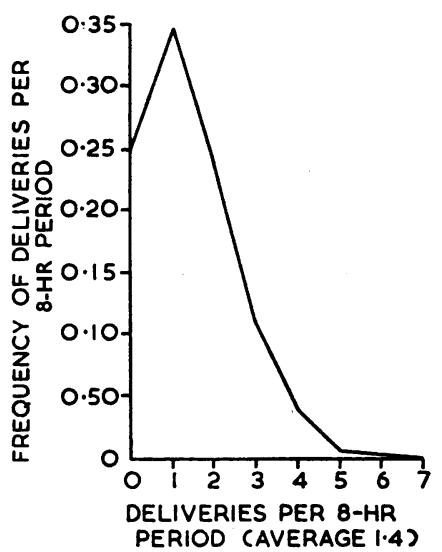

Fig. 5.-Theoretical distribution of deliveries per 8-hr period for general practitioner sector unit.

TABLE IV

SECTOR UNIT

Average daily deliveries $=4 \cdot 1$.

Average deliveries per $8-\mathrm{hr}$ period $=1 \cdot 4$.

\begin{tabular}{c|c|c}
$\begin{array}{c}\text { Deliveries } \\
\text { per 8-hr Period }\end{array}$ & $\begin{array}{c}\text { Poisson Prediction } \\
\text { from Molina's } \\
\text { Tables (z) }\end{array}$ & $\begin{array}{c}\text { Prediction per Year } \\
\text { or per 1,095 Shifts }\end{array}$ \\
\hline 0 & .246597 & $270 \cdot 00$ \\
1 & .345236 & 378.03 \\
2 & .241665 & $264 \cdot 62$ \\
3 & .112777 & 123.49 \\
4 & .039472 & $43 \cdot 22$ \\
5 & .011052 & $12 \cdot 10$ \\
6 & .002579 & $2 \cdot 82$ \\
7 & .000516 & 0.57 \\
8 & .000090 & 0.10 \\
9 & .000014 & 0.02 \\
$10+$ & & 0.00 \\
\hline
\end{tabular}


The probability of this occurrence is .000106 or eleven in 100,000 8-hr shifts or once in every 8 years.

We decided that a more reasonable basis might be to consider the probability of six or more patients arriving in a single 8-hr period. The probability of this event occurring is .0032 or 32 times in 10,000 8-hr shifts, or once in $3 \frac{1}{3}$ months (Fig. 5; Table IV).

We wished next to decide upon the number of day-stay delivery rooms which would satisfy most of the expected case load, without over-providing for comparatively rare events. Table $V$ shows percentage satisfaction given by varying numbers of rooms, based on a mean expectancy of $4 \cdot 1$ deliveries per day.

TABLE V

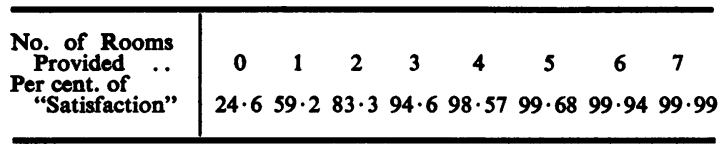

The word "satisfaction" refers to the proportion of 8-hr periods on which the demand is met.

Since the probability of eight or more deliveries occurring in a single 8-hr shift is only once in every 8 years, it seemed more reasonable to provide six day-stay delivery rooms. This number would satisfy (Table V) 99.94 per cent. of the load falling upon the unit. Although the percentage satisfaction given by five day-stay delivery rooms is only 0.26 per cent. less than that given by six such rooms, or 99.68 per cent. of the load falling upon the unit, we felt an allowance should be made for rooms being out of commission for cleaning and maintenance purposes.

It may well be that up to 50 per cent. of the patients received will have medical criteria which will entail their transfer to a lying-in ward before the completion of their 24-hr stay. This will add to the tolerance already allowed, since the calculations have been based upon the assumption that all those entering the unit will be 24-hr stay normal cases, occupying one room only. However, it should be noted that, should the rooms be occupied for an 8-hr period only, the six rooms would provide 99.94 per cent. satisfaction for the frequency demands falling upon the unit (see Table IV).

\section{ConClusion}

We have demonstrated the application of one particular statistical method to an individual unit, and we hope that this will also show how statistical techniques can aid planning. The application of similar methods to other parts of the hospital may yield fruitful results. The analysis of casualty load, and the amount of direct nursing care needed in a traditional ward throughout the year, are examples. However, for this particular technique, the criteria of random loading must be borne in mind. Flagle (1960) suggested that illness in the community follows a random distribution. But at most stages of care selective factors are at work. Referral to the out-patient department; referral from other hospitals; theatre timings; $x$-ray appointments; and the like, eliminate the quality of random loading, which is essential to the application of a Poisson process.

\section{SUMMARY}

The distribution of case load upon a maternity hospital delivery suite is discussed. Prediction of such a load according to a Poisson distribution is shown to be possible. The derivation of the number of delivery rooms is discussed and the probability of full occupancy is demonstrated.

[Since this paper was prepared, changes in the national birth rate have altered the numerical estito mates of rooms needed, etc. However, the methods and basis of calculation remain unchanged and valid.]

We wish to acknowledge the help of Lord Llewelyn-Davies of the Department of Architecture, University College, London, in preparing this paper. We wish to thank Dr R. H. Cawley of the Institute of Psychiatry and Miss Irene Foster of the Department of Architecture, University College, London, for valuable statistical advice.

\section{REFERENCES}

Blumberg, M. S. (1961). Mod. Hosp., 97, 75.

Flagle, C. D. (1960). In" 'Operations Research and Systems Engineering", ed. C. D. Flagle, W. H. Huggins, and R. H. Roy, p. 444. Johns Hopkins Press, Baltimore.

Ministry of Health (1959). "Report of the Maternity Services Committee", p. 26. H.M.S.O., London.

Molina, E. C. (1942). “Poisson's Exponential Binomial Limit". Van Nostrand, New York.

Thompson, J. B., Avant O. W., and Spiker, E. D. (1960). Mod. Hosp., 94, 75. 